\title{
PERIODIC MOTIONS IN WEDDELL SEA PACK ICE
}

\author{
by
}

\author{
M.A. Rowe, ${ }^{*}$
}

(Scott Polar Research Institute, University of Cambridge, Lensfield Road, Cambridge CB2 1ER, England, U.K.)

$$
\text { C.B. Sear, }{ }^{\dagger} \text { S.J. Morrison, }
$$

(British Antarctic Survey, Natural Environment Research Council, High Cross, Madingley Road, Cambridge CB3 OET, England, U.K.)

$$
\text { P. Wadhams, }
$$

(Scott Polar Research Institute, University of Cambridge, Lensfield Road, Cambridge CB2 1ER, England, U.K.)

D.W.S. Limbert,

(British Antarctic Survey, Natural Environment Research Council, High Cross, Madingley Road, Cambridge CB3 OET, England, U.K.)

and

D.R. Crane

(Scott Polar Research Institute, University of Cambridge, Lensfield Road, Cambridge CB2 IER, England, U.K.)

\section{ABSTRACT}

Position data from an Argos-tracked buoy deployed in the southern Weddell Sea in the austral summer of 1986 are analysed to determine important time-scales of variation of sea-ice motion in the seasonal sea-ice zone. Quality control and pre-processing of raw buoy data are discussed. Processed position data are subjected to time- and frequency-domain analyses. These highlight the importance of diurnal and semi-diurnal periodicities in the buoy motion. These preferred periodicities are associated with tidal forcing rather than wind forcing or inertial oscillations. Periodograms of the longitudinal component of buoy motion indicate that the power of the $24 \mathrm{~h}$ tidal component drops dramatically around day 130 in 1986. The possible causes of this are discussed and it is concluded that internal resistance within the sea-ice field may have increased at that time.

\section{INTRODUCTION}

As part of the Winter Weddell Sea Project 1986 (WWSP 86), the British Antarctic Survey (BAS) and the Scott Polar Research Institute, University of Cambridge (SPRI), deployed two ice-strengthened surface-drifting buoys in sea-ice floes in the Weddell Sea. Sensor data and buoy location were transmitted via satellite to Service Argos, where these data were processed. Sub-sets of these data were also sent by Service Argos to the Global Telecommunication System (GTS) for distribution to meteorological centres. The intention was to determine the tracks of these buoys and to collect data on surface

*Present address: Robert Hooke Institute, Department of Atmospheric, Oceanic and Planetary Physics, Clarendon Laboratory, University of Oxford, Parks Road, Oxford, OX1 3PU, England, U.K.

†Present address: SAIC Polar Oceans Associates, 16 Miller's Yard, 10/11 Mill Lane, Cambridge CB2 1RQ, England, U.K. meteorological conditions in this data-sparse region. The buoys formed a part of a basin-scale array which was completed by other buoys deployed in the south-east Weddell Sea during a later phase of WWSP 86 . The deformation of this array is being studied in order to give information on the large-scale dynamics of the Weddell Sea pack ice (Wadhams and others, 1989).

The work reported here began when data became available from the first buoy to be deployed (in the southern Weddell Sea). The buoy track showed evidence of periodic motions which were believed to be tidal in origin. As very few tidal current measurements have been made in this region, this information was regarded as potentially of great value. A secondary aim was to assess the feasibility of deducing ice-compactness information from the modulations of the periodic signal. The overall motion of the buoy and comparison with other deployments are discussed in Limbert and others (1989).

\section{TIDES}

There are very few tidal data from the Weddell Sea and most of those available are restricted to surfaceelevation (or bottom-pressure) measurements and do not give information on tidal currents. The accessible information on the tidal regime in the Weddell Sea is summarized in Table I. The dominant tidal signals appear to be at both diurnal $\left(\mathrm{K}_{1}\right)$ and semi-diurnal $\left(\mathrm{M}_{2}\right)$ periods. Tidal currents range from $1 \times 10^{-2} \mathrm{~m} \mathrm{~s}^{-1}$ in the deep ocean to $2.56 \mathrm{~m} \mathrm{~s}^{-1}$ on the shelf. These speeds imply tidal excursions with an amplitude of several kilometres.

\section{DATA AND ANALYSIS}

Two Polar Research Laboratory Argos-tracked meteorological buoys were deployed on multi-year ice in the Weddell Sea for a joint SPRI/BAS programme.

(i) "Southern Buoy" (0534) Deployed December 1985; yielded data to April 1987. 


\begin{tabular}{|c|c|c|c|c|c|c|c|c|}
\hline \multicolumn{2}{|c|}{ Position } & Depth & $\begin{array}{c}\text { Main } \\
\text { constituent }\end{array}$ & $\begin{array}{l}\text { Maximum } \\
t \text { amplitude }\end{array}$ & $\begin{array}{l}\text { Other } \\
\text { constituents }\end{array}$ & $\begin{array}{l}\text { Record } \\
\text { length }\end{array}$ & Instrument & Reference \\
\hline lat. & long. & $\mathrm{m}$ & & $\mathrm{cm} \mathrm{s}^{-1}$ & & d & & \\
\hline $66^{\circ} 29^{\prime} \mathrm{S}$ & $41^{\circ} 02^{\prime} \mathrm{W}$ & 4540 & $\mathrm{M}_{2}$ & 1 & $\mathrm{O}_{1} \mathrm{~K}_{1} \mathrm{~S}_{2}$ & 350 & $\mathrm{c} \mathrm{m}$ & $\begin{array}{l}\text { Middleton and } \\
\text { Foster, } 1977\end{array}$ \\
\hline $74^{\circ} \mathrm{S}$ & $40^{\circ} \mathrm{W}$ & 660 & $\mathrm{~K}_{1}$ & 40 & $\mathrm{O}_{1} \mathrm{M}_{2} \mathrm{~S}_{2}$ & 460 & $2 \times \mathrm{cm}$ & $\begin{array}{l}\text { Foldvik and } \\
\text { Kvinge, } 1974\end{array}$ \\
\hline $77^{\circ} 07^{\prime} \mathrm{S}$ & $49^{\circ} 03^{\prime} \mathrm{W}$ & 240 & - & 40 & $\begin{array}{l}\text { diurnal/semi- } \\
\text { diurnal }\end{array}$ & 4.5 & $\underset{\mathrm{bpr}}{\mathrm{c}}$ and & $\begin{array}{l}\text { Gammelsrød } \\
\text { and Slotsvik, } \\
1981\end{array}$ \\
\hline $70^{\circ} 30^{\prime} \mathrm{S}$ & $2^{\circ} 32^{\prime} \mathrm{W}$ & $\begin{array}{l}\text { Norway } \\
\text { station }\end{array}$ & $\mathrm{M}_{2}$ & - & $\mathrm{O}_{1} \mathrm{~K}_{1} \mathrm{~S}_{2}$ & 3.2 & $\operatorname{tg}$ & $\begin{array}{l}\text { Summary in } \\
\text { Foldvik and } \\
\text { Kvinge, } 1974\end{array}$ \\
\hline $77^{\circ} 59^{\prime} \mathrm{S}$ & $37^{\circ} 10^{\prime} \mathrm{W}$ & Shackleton & $\mathrm{M}_{2}$ & - & $\mathrm{O}_{1} \mathrm{~K}_{1} \mathrm{~S}_{2}$ & 51 & grav & $\begin{array}{l}\text { Summary in } \\
\text { Foldvik and } \\
\text { Kvinge, } 1974\end{array}$ \\
\hline $77^{\circ} 43^{\prime} \mathrm{S}$ & $41^{\circ} 08^{\prime} \mathrm{W}$ & Ellsworth & $\mathrm{M}_{2}$ & - & $\mathrm{O}_{1} \mathrm{~K}_{1} \mathrm{~S}_{2}$ & 32 & grav & $\begin{array}{l}\text { Summary in } \\
\text { Foldvik and } \\
\text { Kvinge, } 1974\end{array}$ \\
\hline
\end{tabular}

Tidal constituents

c $\mathrm{m}$, current meter.

bpr, bottom-pressure recorder.

tg, tide gauge.

grav, gravimetric.
$\mathrm{M}_{2}$, lunar semi-diurnal

$\mathrm{S}_{2}$, solar semi-diurnal

$\mathrm{O}_{1}$, lunar diurnal

$\mathrm{K}_{1}$, lunar/solar diurnal
$12.42 \mathrm{~h}$

$12.00 \mathrm{~h}$

$25.82 \mathrm{~h}$

$23.93 \mathrm{~h}$ (ii) "Northern Buoy" (1533) Deployed March 1986; yielded data to September 1986.

Details of the buoy instrumentation are given in Wadhams and others (1989). Only data from the "Southern Buoy" are used here.

The data from buoys 0534 and 1533 were provided by Service Argos on magnetic tapes. These contained position determinations and data transmitted by means of the NOAA/TIROS-N satellites. As these satellites are in polar orbits, the frequency with which a satellite is above an observer's horizon increases dramatically towards the poles. Each satellite pass over the Weddell Sea buoys took approximately $20 \mathrm{~min}$, with data logging from the buoy sensors every minute. Most of the time a total of at least 20 passes/d occurred over buoy 0534 from two satellites, each with orbital period $100 \mathrm{~min}$. The resultant data and position fixes are irregularly spaced in time. The number of passes/d decreases as a function of decreasing latitude and this was evident as the buoys moved north.

\section{PROCESSING}

The main considerations in processing the raw data were to remove instrumental and data-transmission errors, while retaining the original temporal sampling. Each pass of a single satellite over the buoy's horizon yielded a stream of sensor data (referred to by Service Argos as a data flow) and a single position fix with an associated time. Data outside specified limits (determined before deployment for each sensor) were rejected. A median filter smoothing was then performed, selecting one datum for each sensor in each flow. Median filters have been shown (Sy, 1985) to be particularly effective in removing data spikes whilst allowing most of the signal to pass without aliasing. The algorithm used here also distinguishes overlapping flows (where two satellites are both above the buoy's horizon) and resequences flows which are not time sequential). Each data value chosen by this algorithm is then associated with the buoy position calculated during the corresponding satellite pass and a time. Two times were used: the time Argos assigns to the position and the median of the sensor times. For this paper, only position data were needed and so the Argos position time was used. However, where multiple sensor data are being used, the position and data values are normally both associated with the median of the sensor times.

\section{Accuracy}

Of great importance to the study of drifting buoy tracks is the accuracy of the Argos position fixes. Two sources of error are identified by Argos which limit location accuracy. The first is error related to Service Argos (inaccuracies in the calculated geometry of the satellite orbit and time coding) and the second is platform-related error. Short-term instabilities in the oscillator (less than $10^{-1} \mathrm{~s}$ ) cause inaccuracies in the calculation of the doppler effect and result in random errors in location. Longer time-scale instabilities (intra-pass $O(20 \mathrm{~min})$ and inter-pass $O(100 \mathrm{~min})$ ) also affect location calculation. Inaccuracies may also result from variations in the altitude of the buoy, its velocity, and fluctuations in ambient temperature. The cumulative effect of all these errors leads to an accuracy of $\pm 200-300 \mathrm{~m}$ in the position fixes. On occasions, this error may be larger than the distance moved between passes by a slow-moving, ice-bound buoy.

\section{Subsequent quality control}

A result of the inaccuracies in the Argos position fixes is that in calculating buoy velocities it is necessary to ensure that only one location is used in any $20 \mathrm{~min}$ interval, otherwise spurious large velocities may be calculated. As a further quality control, outlying velocities greater than $5 \mathrm{~m} \mathrm{~s}^{-1}$ were removed from the velocity data set.

\section{Time-domain analysis}

As a first step in the time-domain analysis, north and tast components of buoy velocity were generated. Then ouoy-speed and direction data were obtained which were 
binned in $2.07 \mathrm{~h}$ bins. The bin size was chosen so that, if present, the major tidal constituents would be evident. The statistics of the buoy-position data were determined and autocorrelation and time-series analyses were undertaken using the statistical package, MINITAB. Thus, a preliminary assessment of the data could be made which pointed to the further analyses required.

\section{Frequency-domain analysis}

To provide a rapid determination of the main spectral components of the buoy time series, periodograms were generated following the method described by Scargle (1982). The power spectrum for a discrete time series $X\left(t_{i}\right)$ where $i=1,2, \ldots, N_{0}$, is defined following Horne and Baliunas (1986) as:

$P_{X}(\omega)=\frac{1}{2}\left\{\frac{\left[\sum_{j=1}^{N_{0}} X\left(t_{j}\right) \cos \omega\left(t_{j}-\tau\right)\right]^{2}}{\sum_{j=1}^{N_{0}} \cos ^{2} \omega\left(t_{j}-\tau\right)}+\frac{\left[\sum_{j=1}^{N_{0}} X\left(t_{j}\right) \sin \omega\left(t_{j}-\tau\right)\right]^{2}}{\sum_{j=1}^{N_{0}} \sin ^{2} \omega\left(t_{j}-\tau\right)}\right\}^{2}$

where $\tau$ is defined by:

$$
\tan 2 \omega \tau)=\left[\sum_{j=1}^{N_{0}} \sin 2 \omega t j\right]\left[\sum_{j=1}^{N_{0}} \cos 2 \omega t_{j}\right] .
$$

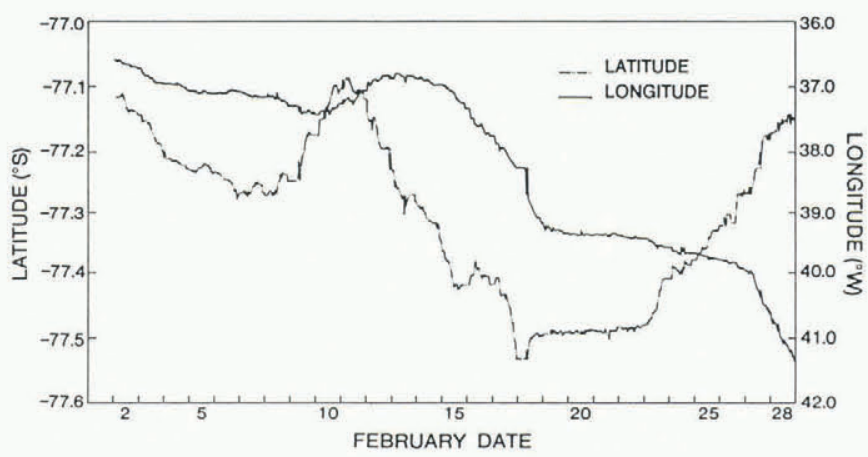

Fig. 2. Time series of latitude and longitude of buoy 0534 during February 1986.

\section{RESULTS}

\section{Time-domain description}

The track of buoy 0534 is shown in Figure 1, together with that of the northern buoy (1533). Initially, the mean motion of buoy 0534 is within the coastal current, following the shelf edge. Then the buoy drifts northward and finally eastward in the Weddell gyre. A more detailed inspection of the buoy motion reveals that, in addition to this basin-scale motion, there are a number of smaller-scale excursions.

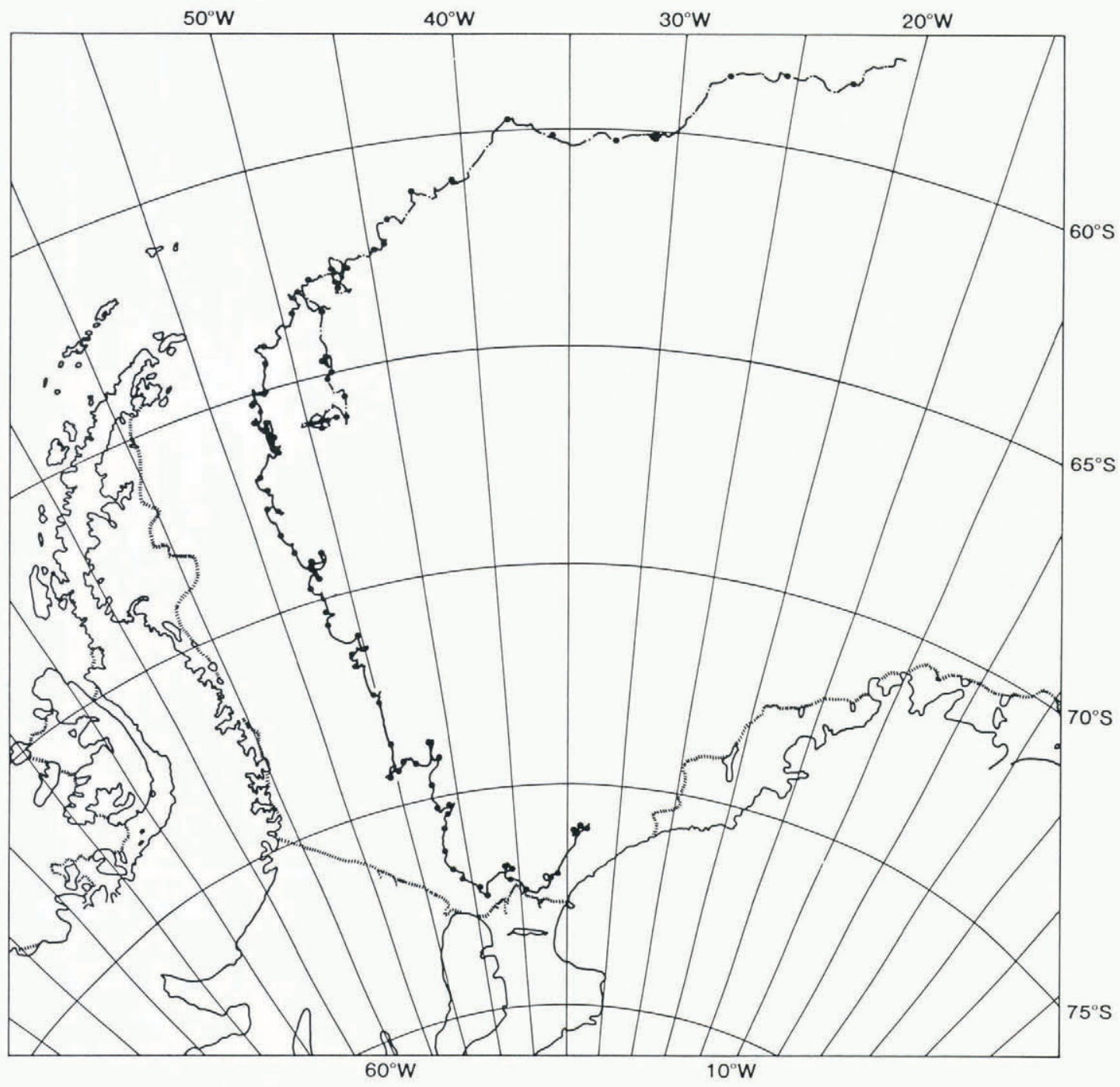

Fig. 1. Complete tracks of SPRI/BAS buoys 0534 (solid line) and 1533 (broken line) throughout their lifetimes with markers every 7 d. Buoy 0534 track starts on 2 January 1986. Buoy 1533 track starts on 7 March 1986. 
These are discussed in companion papers in this volume (Limbert and others, 1989; Wadhams and others, 1989). There is also evidence of diurnal oscillations with an amplitude of order $10 \mathrm{~km}$ (Fig. 2).

The autocorrelation and time-series analyses noted above indicated that structure was present in both the speed and phase information in the early part of the time series with peaks in the autocorrelation functions at six and 12 $2.07 \mathrm{~h}$ bins. This suggests that both diurnal and semi-diurnal tidal signals were present while the buoy was in relatively open pack ice. However, these signals had disappeared by later in the year when the buoy was in more compact ice. Following this preliminary analysis of buoy velocity and in order to investigate further the small periodic motions of the buoy, a frequency-domain analysis was employed.

\section{Frequency-domain description}

A visual inspection of a month-long section of the buoy track indicates the presence of periodic motions with a period of approximately $24 \mathrm{~h}$. To study these periodicities in more detail, periodograms were calculated following Scargle (1982), as described above. Two such periodograms of longitude and latitude variations are shown in Figures 3 and 4 , respectively. The longitudinal component of the buoy motion has larger amplitudes than the latitudinal component. Thus, only this component is discussed in detail here. It is clear that a major spectral peak exists at diurnal periods and there is a weak indication of semi-diurnal motion.
In addition to seeking to explain the origins of these motions, it is also instructive to consider the variations of these periodic motions with time. To achieve this, periodograms covering successive $10 \mathrm{~d}$ periods were generated. Figure 5 shows six of these which are for 1986, days $73-82, \quad 83-92, \quad 123-132, \quad 133-142, \quad 153-162$, and 193-202. The periodograms shown illustrate what is clear from the full set of plots: that the power of the dominant $24 \mathrm{~h}$ periodicity remained relatively constant for about $130 \mathrm{~d}$. After this, there was a sudden reduction of greater than one order of magnitude, to a new level which persisted for the next $100 \mathrm{~d}$ during the Antarctic winter. After day 223, the power of the $24 \mathrm{~h}$ peak returned to the level of the first $100 \mathrm{~d}$ for the remainder of the record. Periodograms covering successive $20 \mathrm{~d}$ periods were also generated as a procedural check and consistent results were obtained though space does not permit their inclusion here.

\section{DISCUSSION}

The most likely causes of the periodic motions described above are:

(1) wind variations;

(2) inertial oscillations; or

(3) tidal motions.

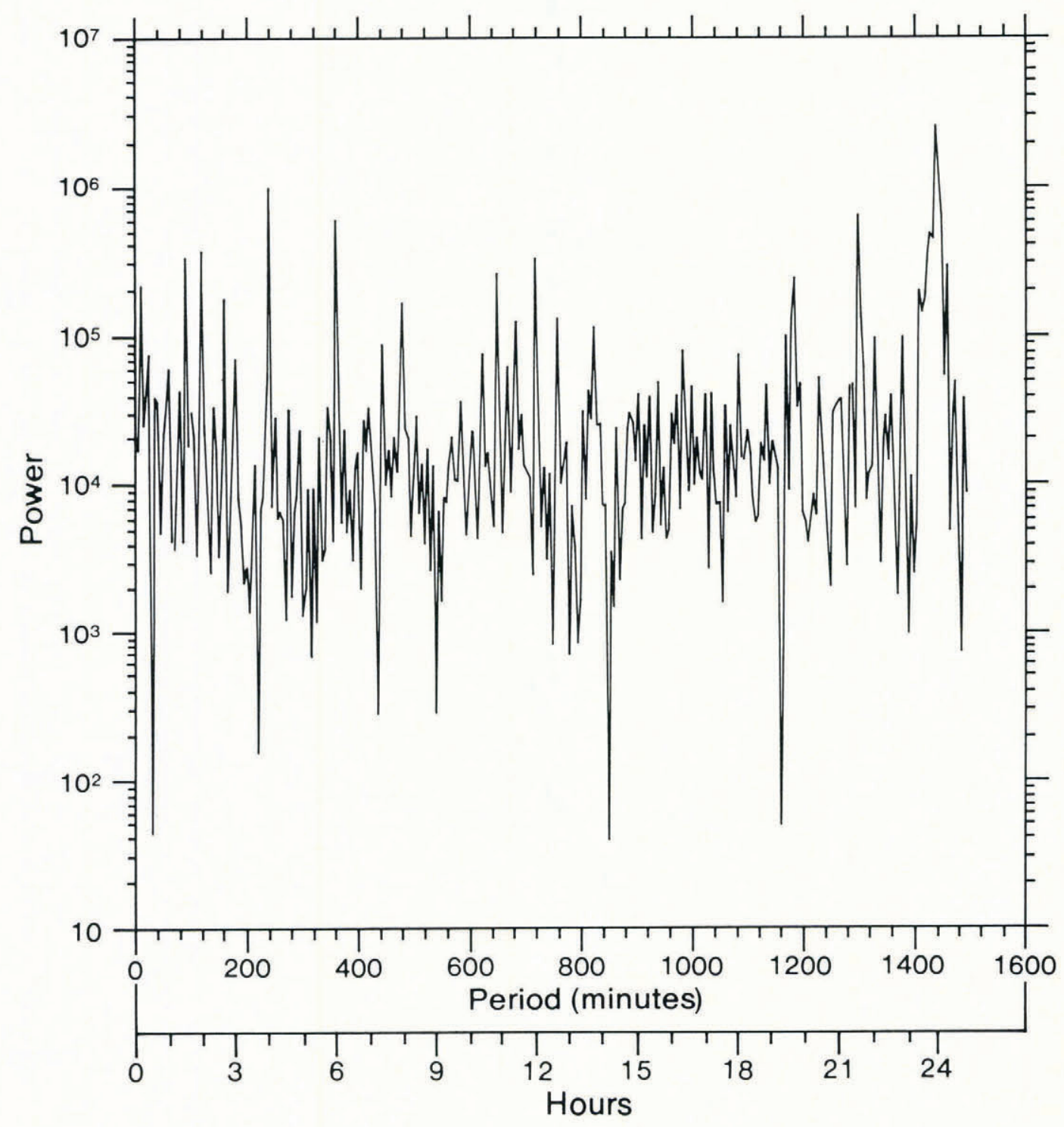

Fig. 3. Periodogram of buoy longitude for periods up to $25 \mathrm{~h}$ using every position fix after quality control for the first 9 months of the time series. Power in $\mathrm{m}^{2} \mathrm{~s}$. The periodogram is drawn from samples of spectral power calculated at $5 \mathrm{~min}$ intervals in periodicity. 


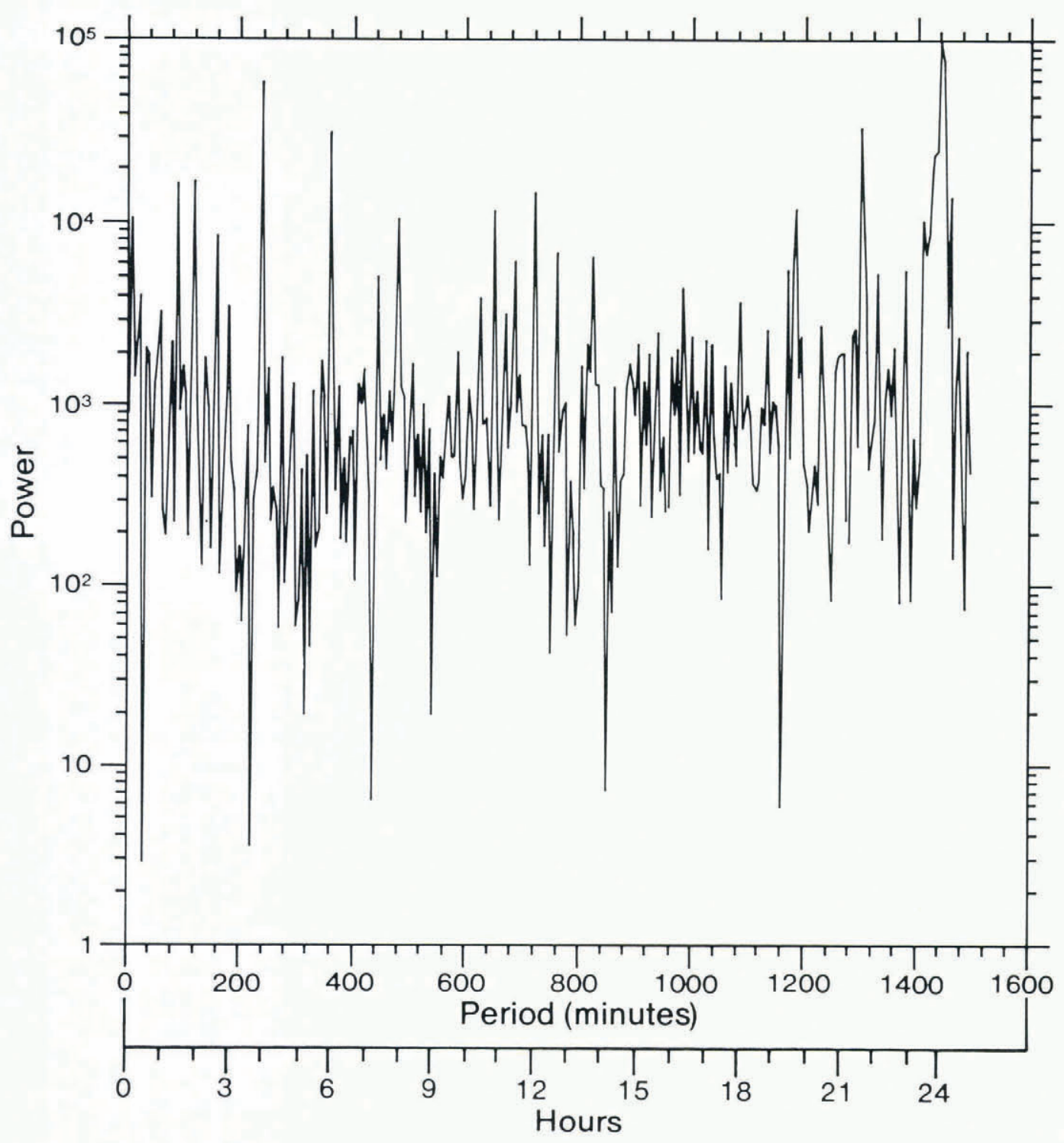

Fig. 4. Periodogram of buoy latitude for periods up to $25 \mathrm{~h}$ using every position fix after quality control for the first 9 months of the time series. Power in $\mathrm{m}^{2} \mathrm{~s}$. The periodogram is drawn from samples of spectral power calculated at $5 \mathrm{~min}$ intervals in periodicity.

The constancy of the power of the diurnal spectral peak in the periodograms suggests that the wind is not responsible and a frequency-domain analysis of the wind speed measured on the buoy (not shown) indicated that the spectrum was white (very high-frequency components dominated) over the same range of periods.

The inertial period at $75^{\circ} \mathrm{S}$ is $12.424 \mathrm{~h}$. This is very close to the lunar semi-diurnal tidal period $\left(\mathrm{M}_{2}\right)$ of $12.421 \mathrm{~h}$. In fact, the periods are so close as to make their separation by spectral methods impracticable. However, a feature of inertial oscillations is that they are likely to be excited by changes in wind velocity and then to show a decay in amplitude. A consequence of this is that the phase of these inertial motions will vary irregularly. The dominance of the power of the diurnal spectral peak over the $12 \mathrm{~h}$ peak in the spectra must be interpreted as showing that the main periodicity is at about $24 \mathrm{~h}$. Furthermore, as already mentioned, the spectra of buoy positions are remarkably consistent from one $10 \mathrm{~d}$ period to the next, and so inertial motions are unlikely to be the major component. Thus, a process of elimination suggests that tidal motions are likely to be responsible for the periodic motions observed. The amplitude and periodicities observed are certainly within the range of existing tidal measurements summarized in Table $\mathrm{I}$.

\section{ICE COMPACTNESS}

Buoy 0534 was deployed in relatively ice-free conditions (approximately six-tenths cover). As the summer progressed, the U.S. Navy-NOAA Joint Ice Center sea-ice charts showed that the ice cover decreased to its minimum extent at the end of March before starting rapid growth through April and May. By mid-May 1986, the whole of the Weddell Sea was covered by nine- to ten-tenths ice, extending to $65^{\circ} \mathrm{S}$. Thereafter, the ice extent remained fairly constant and the interior ice cover in the region of the buoy did not reduce until the begining of November. The sudden reduction in the power of the $24 \mathrm{~h}$ periodicity indicated by the $10 \mathrm{~d}$ periodograms occurred between day 120 and 140. Subsequently, the power did not increase until between day 220 and 240 in the spring. For a substantial part of this period (day 180-200), the mean motion of the buoy was completely different to that in the rest of the time series. Northward motion essentially stopped and there was a westward translation of $200 \mathrm{~km}$ followed by a period of no mean motion. At that time, the buoy appears still to have been over the continental shelf and the change coincided with its movement to a position over a shallower region at $74^{\circ} \mathrm{S}, 48^{\circ} \mathrm{W}$. At this stage, it is only possible to speculate about the cause of the change in the buoy motion. 

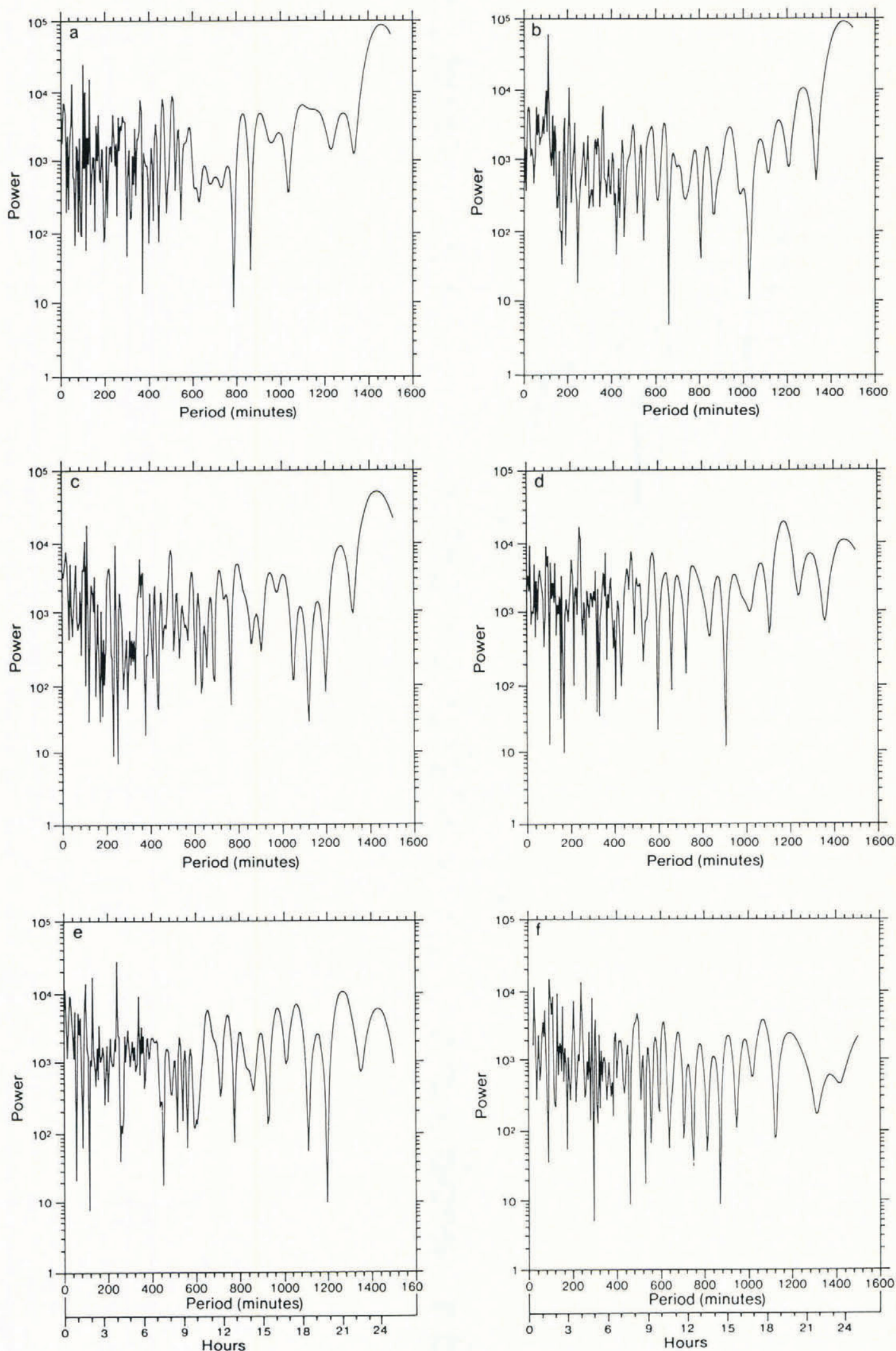

Fig. 5. Periodograms of buoy longitude, each covering individual $10 \mathrm{~d}$ periods during 1986: (a) days 73-82; (b) days 83-92; (c) days 123-132; (d) days 133-142; (e) days 153-162; and (f) days 193-202. Power in $\mathrm{m}^{2} \mathrm{~s}$. Each periodogram is drawn from samples of spectral power calculated at $5 \mathrm{~min}$ intervals in periodicity.

However, the coincidence of this change with the reduction in the excursions of the buoy may indicate that the ice field became compressed towards the quasi-permanent sea-ice cover close to the east coast of the Antarctic Peninsula and thus that internal resistance within the ice pack caused the suppression of the excursions as the buoy slowed and moved westward.

\section{CONCLUSION}

Position data from a buoy deployed in sea ice in the Weddell Sea have been used to determine important time-scales of variation of sea-ice motion. Time- and frequency-domain analyses of buoy-position data have highlighted the importance of diurnal and semi-diurnal 
periodicities in the buoy motion. These preferred periodicities are associated with tidal forcing rather than wind forcing or inertial oscillations. Periodograms of the longitudinal component of buoy motion indicate that the power of the $24 \mathrm{~h}$ tidal component drops, by approximately one order of magnitude, around day 130 in 1986, remaining low for approximately $100 \mathrm{~d}$ during the Antarctic winter. It is concluded that changes in bottom topography along the buoy track or, more likely, increased internal ice resistance within the sea-ice pack are the most likely causes of the reduction in the power of the tidal signal. This analysis of periodic motions in a single buoy track suggests a novel method for making a measure of ice interactions. Furthermore, the use of remotely sensed buoy data is seen to offer a potentially powerful method for the measurement of tidal currents in remote regions.

\section{ACKNOWLEDGEMENTS}

We are grateful to V. Squire, Department of Mathematics and Statistics, University of Otago, for his contributions to this project while at the SPRI. We also thank R. Muench, Science Applications International Corporation, Bellevue, Washington, for deploying buoy 1533 in the Weddell Sea. We are indebted to D. Warren of BAS for discussion and constructive criticism of our methods of analysis. P.W., D.R.C., and M.A.R. are grateful for the support of the U.K. Natural Environment Research Council under grant GR3/5713A.

\section{REFERENCES}

Foldvik, A. and T. Kvinge. 1974. Bottom currents in the Weddell Sea: results of long time current meter moorings at $74^{\circ} \mathrm{S} 40^{\circ} \mathrm{W}$, during IWSOE 1968-1973. Univ. Bergen Geophys. Inst. Div. A. Phys. Oceanogr. Rep. 37.

Gammelsrød, T. and N. Slotsvik. 1981. Hydrographic and current measurements in the southern Weddell Sea 1979/80. Polarforschung, 51(1), 101-111.

Horne, J.H. and S.L. Baliunas. 1986. A prescription for period analysis of unevenly sampled time series. Astrophys. J., 302, 757-763.

Limbert, D.W.S., S.J. Morrison, C.B. Sear, P. Wadhams, M.A. Rowe, and D.R. Crane. 1989. Pack-ice motion in the Weddell Sea in relation to weather systems and determination of a Weddell Sea sea-ice budget. Ann. Glaciol., 12, 104-112.

Middleton, J.H. and T.D. Foster. 1977. Tidal currents in the central Weddell Sea. Deep-Sea Res., 24(12), 1195-1202.

Scargle, J.D. 1982. Studies in astronomical time series analysis. II. Statistical aspects of spectral analysis of unevenly spaced data. Astrophys. J., 263, 835-853.

Sy, A. 1985. An alternative editing technique for oceanographic data. Deep-Sea Res., 32A(12), 1591-1599.

Thorndike, A.S. 1986. Kinematics of sea ice. In Untersteiner, N., ed. The geophysics of sea ice. New York, Plenum Press, 489-549.

Wadhams, P., C.B. Sear, D.R. Crane, M.A. Rowe, S.J. Morrison, and D.W.S. Limbert. 1989. Basin-scale ice motion and deformation in the Weddell Sea during winter. Ann. Glaciol., 12, 178-186. 